\title{
Effect of temazepam on tracheobronchial mucus clearance
}

\author{
A Hasani, M A Spiteri, D Pavia, M T Lopez-Vidriero, J E Agnew, S W Clarke
}

\begin{abstract}
Background Tracheobronchial clearance of mucus from the lungs is reduced during sleep and, usually, by the administration of opiates. It seemed possible therefore that temazepam, a widely used potent benzodiazepine, retarded clearance.

Methods The effect of $10 \mathrm{mg}$ temazepam on mucociliary clearance was studied in eight healthy volunteers, aged 18-50 (mean 30) years, in a randomised, placebo controlled, double blind, crossover study. Six subjects were female and two male. Six were non-smokers and two were light current smokers. Clearance was assessed from the change in radioactivity in the lungs after inhalation of $5 \mu \mathrm{m}$ diameter polystyrene particles, labelled with technetium-99m, under controlled conditions.

Results Tracheobronchial clearance was reduced by $22 \%$ after temazepam by comparison with placebo during the first three hours after drug ingestion; this is the period when circulating drug concentrations are highest.

Conclusion Temazepam should be prescribed with caution in patients with impaired lung mucociliary transport.
\end{abstract}

Temazepam, a benzodiazepine, is extensively prescribed in general and hospital practice to induce sleep. ${ }^{1}$ It also possesses powerful anxiolytic, muscle relaxant, and anticonvulsant activity.

Mucociliary clearance ${ }^{2}$ is a non-specific host defence clearance mechanism, which together with cough ${ }^{3}$ helps to keep the lungs clean and sterile even when exposed to a polluted environment. Clearance may be adversely affected by several factors, ${ }^{4}$ including lung diseases, such as chronic bronchitis and asthma, and pharmacological agents, such as $\beta$ blocking and anticholinergic drugs.

With a few exceptions, ${ }^{5}$ opiates appear to depress mucociliary clearance ${ }^{6}$ and they inhibit mucus secretion in human bronchi. ${ }^{7}$ Narcotics reduce ciliary activity of the oyster gill. ${ }^{8}$ Codeine and normethadone depress ciliary beat frequency in a dose dependent fashion in animals, ${ }^{9}$ and subcutaneous codeine and morphine slow tracheobronchial clearance in the cat for several hours. ${ }^{10}$

Lung mucociliary clearance and cough are reduced in normal subjects and asthmatic patients during sleep. ${ }^{11}$ The effect of benzodiazepine on lung mucociliary clearance in man has not been described previously.

We report the effect of a single dose of temazepam on lung mucociliary clearance in healthy volunteers.

\section{Methods}

SUBJECTS

Eight healthy volunteers (six female, two male) participated in the study. Their mean (SE) age, height, and weight were 30 (4) years, $1.64(0.03)$ $\mathrm{m}$, and 65 (4) kg. Six subjects were nonsmokers and two (both women) were current smokers with a tobacco consumption of six and eight pack years.

\section{METHODS}

A double blind, randomised, placebo controlled, crossover, within subject study was carried out. The volunteers attended the laboratories on two separate study days at least one week apart. On arrival in the laboratory their forced expiratory volume in one second $\left(\mathrm{FEV}_{1}\right)$, forced vital capacity (FVC), and maximum mid expiratory flow $\left(M_{M} F_{25-75}\right)$ were measured with a dry bellows spirometer (Vitalograph) and their peak expiratory flow (PEF) with a Wright's peak flow meter. For each pulmonary function index the highest value of three technically acceptable measurements was recorded.

Tracheobronchial clearance was measured by an objective, non-invasive radioaerosol technique. ${ }^{12}$ Under strictly controlled conditions, subjects inhaled $5 \mu \mathrm{m}$ monodisperse polystyrene particles labelled firmly with the gamma emitting radionuclide technetium-99m ${ }^{99 m} \mathrm{Tc}$; half life six hours). The radioaerosol was inhaled in discrete breaths of $450 \mathrm{ml}$ each from around functional residual capacity. Each breath was followed by a three second breath holding pause to allow particles to be deposited by gravity. ${ }^{13}$ Inspiratory flow was measured by a pneumotachygraph and recorded on an ultraviolet recorder. After the inhalation of radioaerosol subjects were asked to rinse their mouth with water to clear the oropharyngeal region of radioaerosol and they subsequently swallowed some water to rinse the oesophagus. Immediately after inhalation the subjects were seated between two suitably collimated scintillation counters located anteroposteriorly to the chest. The field of view of these detectors included most of both lungs but excluded radioactivity from the stomach. ${ }^{14}$ Counts were taken at half hour intervals for the next six 
hours with a final count of lung radioactivity at 24 hours.

The radioactivity remaining in the lungs at 24 hours was taken to represent "alveolar deposition"- that is, radioaerosol deposited beyond the reach of mucociliary clearance. ${ }^{15}$ The activity representing alveolar deposition was subtracted from the whole lung count. The tracheobronchial data were expressed as a percentage of the initial count. Tracheobronchial clearance was assessed by measuring the area under the curve (AUC), with the trapezoidal rule, for the first three hours and for the whole six hours of observation. ${ }^{16}$ The area under the curve represents tracheobronchial retention. The larger the AUC the greater is the tracheobronchial retention and the slower the clearance.

Within 10 minutes of the first count the subjects sat in front of a large field of view gamma camera (Ohio-Nuclear 110) linked to a computer (Nodecrest V77-600) and the initial topographical distribution of the radioaerosol within the lungs was expressed quantitatively as a penetration index. ${ }^{17}$ This is defined as the ratio of radioactivity in the outer region of the lungs to that in the inner region divided by the ratio of radioactive krypton-81m (half life 13 seconds) in the two regions.

Fifteen minutes before inhaling the radioaerosol subjects were asked to swallow $5 \mathrm{ml}$ of an elixir (glycerol based) containing $10 \mathrm{mg}$ of temazepam or placebo (the vehicle minus the active drug), which was indistinguishable in taste and appearance from the active preparation.

\section{STATISTICAL ANALYSIS}

As the data were not normally distributed the Wilcoxon test for paired differences was used in the statistical analysis with the Spearman rank correlation test. ${ }^{18}$ The level of significance was taken as $\mathrm{p}<0.05$.

\section{Results}

Five subjects received placebo treatment first and three temazepam. Pulmonary function

Table 1 Mean (SE) baseline pulmonary function indices (expressed as percentages of predicted values) for the eight healthy volunteers on the placebo and temazepam study days

\begin{tabular}{lccl}
\hline & Placebo & Temazepam & $p$ \\
\hline FEV & $115(5)$ & $113(5)$ & NS \\
FVC & $116(5)$ & $114(5)$ & NS \\
PEF & $115(8)$ & $116(7)$ & NS \\
MMF $_{25-75}$ & $95(11)$ & $91(10)$ & NS \\
\hline
\end{tabular}

FEV 1 -forced expiratory volume in one second; FVC-forced vital capacity; PEF-peak expiratory flow; $\mathrm{MMF}_{25-75}$-maximum mid expiratory flow.

Table 2 Mean (SE) radioaerosol inspiratory flow rate, alveolar deposition, and penetration index for the eight healthy volunteers on the placebo and temazepam study days

\begin{tabular}{llll}
\hline & Placebo & Temazepam & $p$ \\
\hline Flow rate (1/min) & $44(3)$ & $37(3)$ & $<0.01$ \\
Alveolar deposition (\%) & $49(3)$ & $52(5)$ & NS \\
Penetration index & $0.65(0.05)$ & $0.70(0.05)$ & NS \\
\hline
\end{tabular}

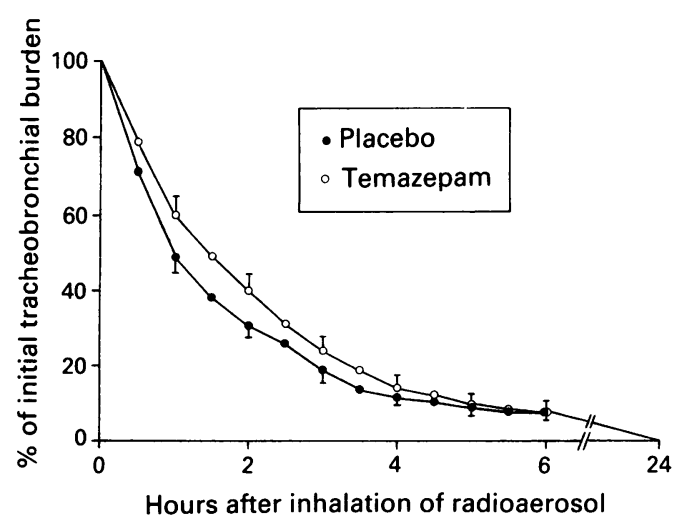

Mean (SE) tracheobronchial retention curves for eight healthy volunteer subjects after placebo and temazepam treatment.

indices were no different after temazepam and after placebo (table 1). The mean (SE) radioaerosol inspiratory flow rate, alveolar deposition, and penetration index for the study group for the placebo and temazepam study days are shown in table 2 . The radioaerosol was inspired at a significantly higher flow rate on the placebo day than on the temazepam day ( $p<0.01)$. There were no significant differences between the two study days for alveolar deposition or penetration index. Three subjects recorded dry, unproductive coughs or throat clearing, or both, during the six hour observation periods on both the placebo and the temazepam days. The frequency of coughing was similar within subjects on the two study days.

Tracheobronchial clearance was significantly slower over the first three hours after treatment with temazepam than with placebo (mean (SE) $\mathrm{AUC}_{0-3} 132 \%(11 \%) / \mathrm{h}$ for placebo and $161 \%$ $(10 \%) / h$ for temazepam; $p<0.05)$. Although the $\mathrm{AUC}_{0-6}$ for the six hour observation period (figure) was greater (that is, clearance was slower) after temazepam $(200 \%(16 \%) / \mathrm{h})$ than after placebo $(166 \%(15 \%) / \mathrm{h})$ the difference was not significant $(p<0 \cdot 10)$. The correlation coefficient $\left(r_{s}\right)$ for the relation between the dose of drug/unit body weight and percentage change in $\mathrm{AUC}_{0-3}$ was $0.63(\mathrm{p}<0 \cdot 10)$. (The value of $r_{s}$ required for $p<0.05$ is $\mathbf{0 . 6 4}$.)

\section{Discussion}

Tracheobronchial clearance of deposited radioaerosol depends on the initial distribution of the radioaerosol within the lung. This distribution is a function of the physical properties of the aerosol, the mode of inhalation, and the patency of the airways. ${ }^{19}$ The radioaerosol was inspired at a higher flow rate with placebo than with temazepam, but the difference was small and alveolar depositions and penetration indices during the two study days were similar (table 2). Thus the proportions of radioaerosol available for clearance by mucus transport after placebo and temazepam administration were similar.

The AUC was used as an index of tracheobronchial clearance as it reflects clearance over an observation period and avoids multiple statistical testing at numerous time points. 
Lung mucociliary clearance was less (mean percentage increase in AUC $25 \%$ ) during the first three hours after temazepam administration than after placebo. Although a similar reduction in the area under the curve was seen over the six hours of observation it failed to attain statistical significance.

A study on the pharmacokinetics of temazepam elixir in healthy male volunteers showed a mean time to peak plasma concentration of 1.6 hours. ${ }^{20}$ The mean drug distribution and terminal phase half lives were about $1 \cdot 3$ and 9 hours respectively.

The tracheobronchial retention curves diverged over the first two hours after radioaerosol administration, with convergence of the curves thereafter. The maximum separation between the tracheobronchial retention curves occurred at about 1.5 hours, and this coincides with the peak plasma concentrations. Tracheobronchial clearance had returned to normal some five hours after the administration of temazepam, which is before the washout time of the drug is completed (terminal phase $\mathrm{T}^{1} / 2=9$ hours). Neither the half life nor clearance of temazepam is significantly related to age. ${ }^{21}$ Although clearance of total temazepam is higher in men than in women ${ }^{21}$ (on the assumption of complete absorption) this is not relevant to our study, in which six of the eight subjects were women.

The reduction in tracheobronchial clearance after temazepam treatment could have arisen because of altered cough, reduced diaphragm movement, or altered ciliary function. Tracheobronchial clearance comprises mucociliary clearance and cough. The frequency of coughing in the three subjects who did cough was similar on the two study days and was low in two of the three subjects; tracheobronchial clearance must therefore reflect mucociliary clearance in this study.

It has been reported recently that tracheobronchial clearance of patients with bilateral diaphragmatic muscle weakness is less than in healthy control subjects. ${ }^{22}$ Reduced mechanical movement of the lungs after temazepam as a result of a reduced respiratory rate is a possible explanation for the reduction in mucus clearance in our study, though respiratory rate was not measured.

Efficient mucociliary transport depends on the intricate interrelationship between several components of this host defence mechanism, including the integrity of the ciliated epithelium, the thickness and consistency of the periciliary layer, ciliary beat frequency and coordination of the ciliary beat, and the quantity and consistency of the secretions overlying the cilia. Opiates have been reported to reduce ciliary beat frequency ${ }^{10}$ and mucus secretion, ${ }^{7}$ both of which are essential for proper clearance. There is no evidence, however, that temazepam has the same effect.

Tracheobronchial clearance is less in the elderly $^{2324}$ than in younger subjects and in patients with respiratory disease, such as chronic bronchitis, ${ }^{25}$ asthma, ${ }^{26}$ and bronchiectasis. ${ }^{27}$ Sleep will also reduce tracheobronchial clearance in both healthy and asthmatic subjects. A reduction in tracheobronchial clearance must result in retention of lung secretions and may increase the incidence of chest infections ${ }^{28}$ in patients in high risk groups. ${ }^{25-27}$

The administration of temazepam at night in patients with chronic bronchitis, asthma, and bronchiectasis may have an important adverse effect on lung function.

1 Bittencourt P, Richens A. Pharmacokinetics of the hypnotic benzodiazepine, temazepam. Br J Clin Pharmacol 1979, 8:37-8S.

2 Pavia D. Lung mucociliary clearance. In: Clarke SW, Pavia D, eds. Aerosols and the lung. London: Butterworth, 1984: 127-55.

3 Hasani A, Pavia D. Cough as a clearance mechanism. In: Braga PC, Allegra L, eds. Cough. New York: Raven Press, 1989:39-52.

4 Pavia D, Bateman JRM, Clarke SW. Deposition and clearance of inhaled particles. Bull Eur Physiopathol Respir 1980;16:335-66.

5 Lucas AM, Douglas LC. Principles underlying ciliary activity in the respiratory tract. Arch Otolaryngol 1935; 21:285-96.

6 Wanner A. Clinical aspects of mucociliary transport. Am Rev Respir Dis 1977;116:73-125.

7 Roger DF, Barnes PJ. Opioid inhibition of neurally mediated mucus secretion in human bronchi. Lancet 1989; i:930-2.

8 Nomura $S$. Influence of narcotics on ciliary movement of gill of oyster. Proc Soc Exp Biol Med 1928;25:252-4.

9 Hilding AC. Time-lapse relation to changes in the respiratory epithelium after minimal trauma. Acta Otolaryngol 1964;57:352-67.

10 Van Dongen $K$, Leusink $H$. The action of opium-alkaloids and expectorants on the ciliary movements in the air passages. Arch International Pharmacodyn 1953;93: 261-76.

11 Pavia D. Mucociliary clearance at night-Effect of physical activity, posture and circadian rhythm. In: Barnes PJ, Levy J, eds. Nocturnal asthma. London: Royal Society of Medicine, 1984:29-39. (International Congress and Symposium Series No 73.)

12 Pavia D, Bateman JRM, Sheahan NF, Agnew JE, Newman SP, Clarke SW. Techniques for measuring lung mucociliary clearance. Eur J Respir Dis 1980;61 (suppl 110): ciliary c.

13 Agnew JE. Physical properties and mechanisms of deposition of aerosols. In: Clarke SW, Pavia D, eds. Aerosols and the lung. London: Butterworth, 1984:49-70.

14 Thomson ML, Pavia D. Long-term tobacco smoking and mucociliary clearance. Arch Environ Health 1973;26:86-9.

15 Camner P, Philipson K. Human alveolar deposition of $4 \mu \mathrm{m}$ Teflon particles. Arch Environ Health 1978;36:181-5.

16 Pavia D, Agnew JE, Glassman JM, Sutton PP, LopezVedriero MT, Soyka JP, et al. Effects of iodopropylidene glycerol on tracheobronchial clearance in stable, chronic bronchitic patients. Eur J Respir Dis 1985;67:177-84.

17 Agnew JE, Pavia D, Clarke SW. Airways penetration of inhaled radioaerosol: an index to small airways function? Eur J Respir Dis 1981;62:239-55.

18 Siegel S. Nonparametric statistics for the behavioral sciences. Tokyo: McGraw-Hill, 1956

19 Pavia D, Thomson ML, Clarke SW, Shannon HS. Effect of lung function and mode of inhalation on penetration of aerosol into the human lung. Thorax 1977;32:194-7.

20 Pickup ME, Rogers MS, Launchbury AP. Temazepam elixir: comparative bioavailability with a capsule formulation. Int J Pharmaceutics 1984;22:311-19.

21 Divoll M, Greenblatt DJ, Harmatz JS, Shader RI. Effect of age and gender on disposition of temazepam. $J$ Pharmaceutical Sci 1981;70:1104-7.

22 Mier A, Laroche C, Agnew JE, Vora H, Clarke SW, Green $M$, et al. Tracheobronchial clearance in patients with bilateral diaphragmatic weakness. Am Rev Respir Dis 1990;142:545-8.

23 Puchelle E, Zahm JM, Bertrand A. The influence of age on bronchial mucociliary transport. Scand J Respir Dis 1979 60:307-13.

24 Goodman RM, Yergin BM, Landa JF, Golinvaux MH, Sackner MA. Relationship of smoking history and pulmonary function tests to tracheal mucous velocity in non-smokers, young smokers, ex-smokers and patients with chronic bronchitis. Am Rev Respir Dis 1978;117: with chron 14 .

25 Agnew JE, Little F, Pavia D, Clarke SW. Mucus clearance from the airways in chronic bronchitis-smokers and ex smokers. Bull Eur Physiopathol Respir 1982;18:473-84.

26 Bateman JRM, Pavia D, Sheahan NF, Agnew JE, Clarke $\mathrm{SW}$. Impaired tracheobronchial clearance in patients with mild asthma. Thorax 1983;38:463-7.

27 Currie DC, Pavia D, Agnew JE, Lopez-Vidriero MT Diamond PD, Cole PJ, et al. Impaired tracheobronchia clearance in bronchiectasis. Thorax 1987;42:126-30.

28 Gamsu G, Singer MM, Vincent HH, Berry S, Nadel JA. Postoperative impairment of mucous transport in the lung. Am Rev Respir Dis 1976;114:673-9. 